\title{
ANALISIS PERAN KELUARGA SEBAGAI PENGAWAS MINUM OBAT (PMO) PASIEN TB PARU
}

\author{
Wiwit Febrina ${ }^{1}$,Amila Rahmi ${ }^{2}$, \\ ${ }^{1}$ Program Pendidikan Ners, STIKes Fort De Kock, Bukittinggi \\ wiwit.febrina@gmail.com
}

Submitted: 08-05-2017, Reviewer: 09-06-2017, Accepted: 13-08-2018

\begin{abstract}
ABSTRAK
Menurut laporan WHO tahun 2013, diperkirakan terdapat 8,6 Juta kasus TB pada tahun 2012. Upaya pengendalian TB dilakukan dengan menerapkan strategi DOTS. Salah satu dari komponen DOTS (Directly Observed Treatment Short-course) adalah paduan OAT (Obat Anti Tuberkulosis) jangka pendek dengan pengawasan langsung. Untuk menjamin keteraturan pengobatan diperlukan seorang Pengawas Minum Obat (PMO). Keluarga dapat dijadikan sebagai PMO, karena dikenal, dipercaya dan disetujui, baik oleh petugas kesehatan maupun penderita, selain itu harus disegani, dihormati dan tinggal dekat dengan penderita serta bersedia membantu penderita dengan sukarela. Jenis penelitian ini adalah penelitian kualitatif dengan pendekatan fenomenologi yang dilakukan di Puskesmas Ophir. Penelitian ini dilakukan dengan wawancara mendalam terhadap partisipan untuk mengeksplor peran keluarga sebagai Pengawas Minum Obat (PMO). Partisipan diambil secara purposive sampling berjumlah 8 orang terdiri dari 3 orang PMO, 3 Orang Pasien TB Paru, 1 Orang petugas TB Paru Puskesmas, 1 Orang Kepala Puskesmas. Hasil penelitian ini didapatkan adanya empat tema yaitu peran sebagai motivator sudah optimal, peran dalam mengingatkan pemeriksaan ulang sputum sudah optimal, peran pengawasan pengobatan sudah maksimal, sedangkan peran sebagai edukator belum maksimal. Disimpulkan bahwa peran keluarga sebagai PMO bagi pasien TB Paru dalam mengawasi, memotivasi, memastikan pemeriksaan ulang sputum, dan memberikan edukasi kepada pasien TB, akan membantu proses kesembuhan bagi pasien TB Paru. Puskesmas perlu meningkatkan sosialisasi dan penyuluhan terhadap PMO dan pasien TB Paru mengenai penyakit TB Paru serta melakukan monitoring dan evaluasi terkait feedback dari program TB Paru di masyarakat.
\end{abstract}

Kata kunci : Peran Keluarga, Pengawas Minum Obat (PMO), TB Paru

\section{A. PENDAHULUAN}

\section{Latar Belakang}

Menurut deklarasi kedaruratan global (the global emergency) tuberkulosis pada tahun 1993 dari WHO (World Health Organization), sebagian besar negara-negara di dunia tidak berhasil mengendalikan penyakit TB Paru. Menurut WHO (World Health Organization) diperkirakan terdapat 8,6 juta kasus TB pada tahun 2012, dimana 1,1 juta orang diantaranya adalah pasien TB Positif. Diperkirakan $\quad 450.000 \quad$ orang menderita TB MDR (Multi Drugs Resistance) dan 170.000 orang diantaranya meninggal dunia (Kemenkes RI 2002, p.1). WHO (World Health Organization) mengembangkan strategi pengendalian TB termasuk untuk di Indonesia yaitu dengan strategi DOTS (Directly Observed Treatment Short-course). Fokus utama DOTS (Directly Observed Treatment 
Short-course) adalah penemuan dan penyembuhan pasien TB. Salah satu dari komponen DOTS (Directly Observed Treatment Shortcourse) adalah panduan OAT (Obat Anti Tuberkulosis) jangka pendek dengan pengawasan langsung. Untuk menjamin keteraturan pengobatan diperlukan seorang Pengawas Minum Obat (PMO) (PPTI 2010, p.13). Keluarga dapat dijadikan sebagai PMO, karena dikenal, dipercaya dan disetujui, baik oleh petugas kesehatan maupun penderita, selain itu harus disegani, dihormati dan tinggal dekat dengan penderita serta bersedia membantu penderita dengan sukarela. Keluarga dapat dijadikan sebagai PMO (Pengawas Minum Obat), karena dikenal, dipercaya dan disetujui, baik oleh petugas kesehatan maupun penderita, selain itu harus disegani, dihormati dan tinggal dekat dengan penderita serta bersedia membantu penderita dengan sukarela (PPTI 2010, p.13).

Puskesmas Ophir Kabupaten Pasaman Barat, melaksanakan program penanggulangan TB Paru dengan strategi DOTS (Directly Observed Treatment Shortcourse). Strategi DOTS (Directly Observed Treatment Shortcourse) dalam pelaksanaannya mengharuskan adanya seorang PMO yang akan mengawasi pasien dalam proses pengobatan, memberikan edukasi kepada pasien, memberi motivasi, mengantar pasien menjemput obat, bahkan saat pasien tidak mampu datang menjemput obat atau mengantar sputum untuk pemeriksaan follow up pengobatan, keluarga dapat berpartisipasi membantu pasien.

Mengingat pentingnya peran keluarga sebagai Pengawas Minum Obat (PMO) bagi pasien TB Paru, penulis sangat ingin mengeksplorasi peran keluarga sebagai Pengawas
Minum Obat (PMO) pasien TB Paru di Puskesmas Ophir, Kecamatan Luhak Nan Duo, Kabupaten Pasaman Barat.

\section{Tujuan}

Mengeksplorasi peran keluarga sebagai pegawas minum obat (PMO) Pasien TB Paru di Puskesmas Ophir Kecamatan Luhak Nan Duo Kabupaten Pasaman Barat tahun 2016

\section{B. METODE PENELITIAN}

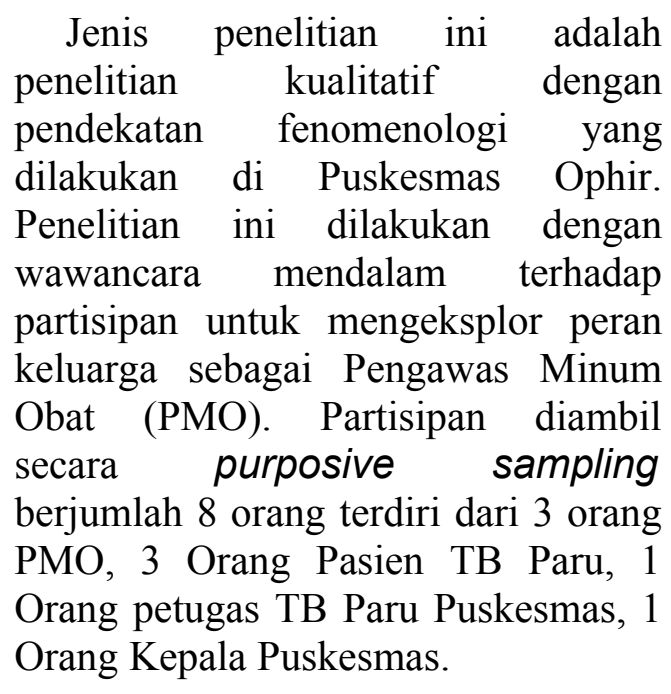

\section{HASIL DAN PEMBAHASAN}

1. Gambaran Umum

Puskesmas Ophir merupakan salah satu Puskesmas di Kabupaten Pasaman Barat. Terletak di Jorong Ophir Nagari Kotobaru. Puskesmas Ophir termasuk dalam wilayah Kecamatan Luhak Nan Duo. Puskesmas Ophir terletak di Kecamatan Luhak Nan Duo, Kabupaten Pasaman Barat, Sumatera Barat. Kecamatan Luhak Nan Duo terdiri dari dua nagari yaitu Nagari Koto Baru dan Nagari Kapa, dan memiliki 14 Jorong di wilayah Kecamatan ini dengan jumlah penduduk sebanyak 39.876 jiwa.

\section{Karakteristik Partisipan}

Partisipan pada penelitian ini berjumlah 8 orang yang terdiri dari 3 orang PMO, 3 Orang Pasien TB Paru, 
1 Orang Pemegang Program TB Paru Puskesmas Ophir, dan 1 Orang Kepala Puskesmas Ophir, Kec. Luhak Nan Duo Kab. Pasaman Barat. Hal ini dimaksudkan agar informasi yang diperoleh sesuai dengan tujuan penelitian yang peneliti lakukan. Untuk menjaga kerahasiaan tentang identitas namanya, masing-masing informan diberi kode sesuai dengan urutan wawancara saat pengumpulan data, dengan kode P1, P2, P3, P4, P5, P6,P7, P8.

\section{Hasil}

Adapun tema-tema yang ditemukan adalah, peran sebagai motivator belum

optimal, peran mengingatkan pemeriksaan ulangsputum sudah optimal, dan peran pengawasan pengobatan sudah maksimal, peran sebagai edukator belum maksimal.

\section{a. Peran sebagai Motivator sudah Optimal}

Berdasarkan hasil penelitian, peran keluarga sebagai motivator sudah optimal. Keluarga sebagai PMO berperan memberikan motivasi atau dorongan agar pasien termotivasi untuk menjalani pengobatan sesuai aturan hingga sembuh. Bentuk peran yang diberikan adalah berupa dukungan moral dan harapan kesembuhan bagi pasien.

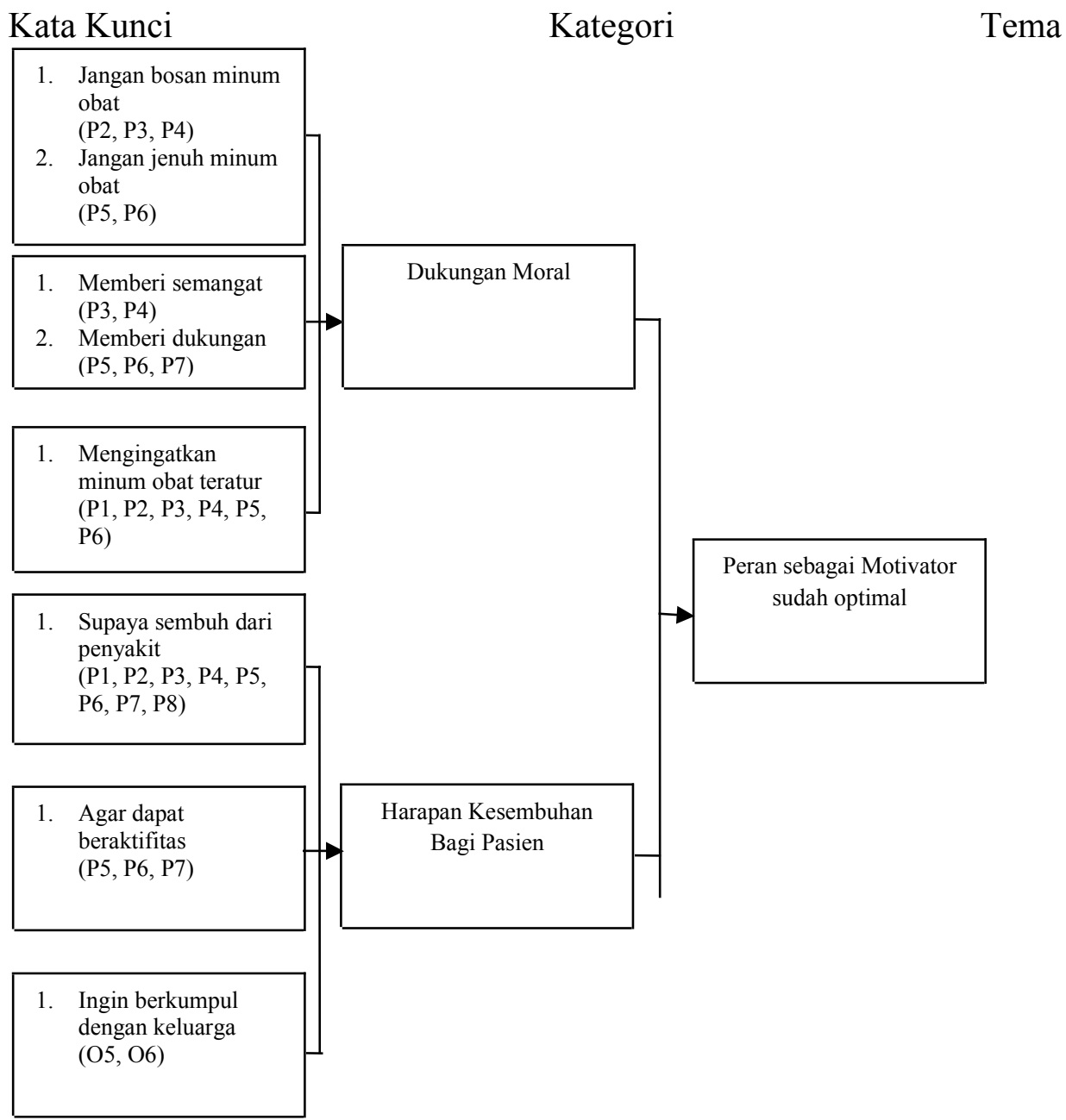

Skema 1

Analisa Tema Peran Keluarga sebagai Motivator 


\section{b. Peran Mengingatkan Pemeriksaan Ulang Sputum sudah Optimal}

Berdasarkan hasil penelitian peran mengingatkan pemeriksaan ulang sputum sudah optimal. Peran keluarga sangatlah penting dalam pemeriksaan ulang sputum, karena hal inilah dapat menentukan sejauh mana keberhasilan pengobatan bagi pasien TB paru. Mengingatkan pemeriksaan ulang sputum dilakukan agar adanya ketepatan jadwal pemeriksaan ulang oleh pasien TB Paru. Peran mengingatkan pemeriksaan ulang juga dilakukan dengan mengantarkan sputum untuk pemeriksaan jika pasien tidak mampu mengantar pada jadwal pemeriksaan
Kata Kunci

Pemeriksaan ulang dahak

dilaksanakan sesuai anjuran

petugas Puskesmas

(P2, P3, P4, P5)

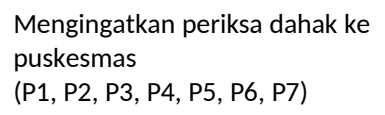

Mengingatkan periksa dahak ke puskesmas

(P1, P2, P3, P4, P5, P6, P7)

Memastikan tangl sesuai kartu TB 02 $(01,03,05)$

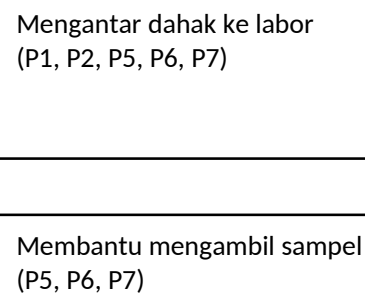

Kategori

Tema
Peran mengingatkan pemeriksaan ulang sputum sudah optimal

Skema 2

Analisa Tema Peran Keluarga Mengingatkan Pemeriksaan Ulang Sputum

\section{c. Peran Pengawasan Pengobatan sudah Maksimal}


Keluarga sebagai PMO sangat berperan dalam mengawasi pengobatan pasien TB Paru di Puskesmas Ophir. Peran pengawasan pengobatan sudah optimal dilakukan oleh keluarga. Peran pengawasan pengobatan di
Puskesmas Ophir dapat diidentifikasi dari ketersediaan obat sesuai kebutuhan pasien, mengingatkan dalam keteraturan minum obat, dan mengawasi jika ada gejala efek samping obat.

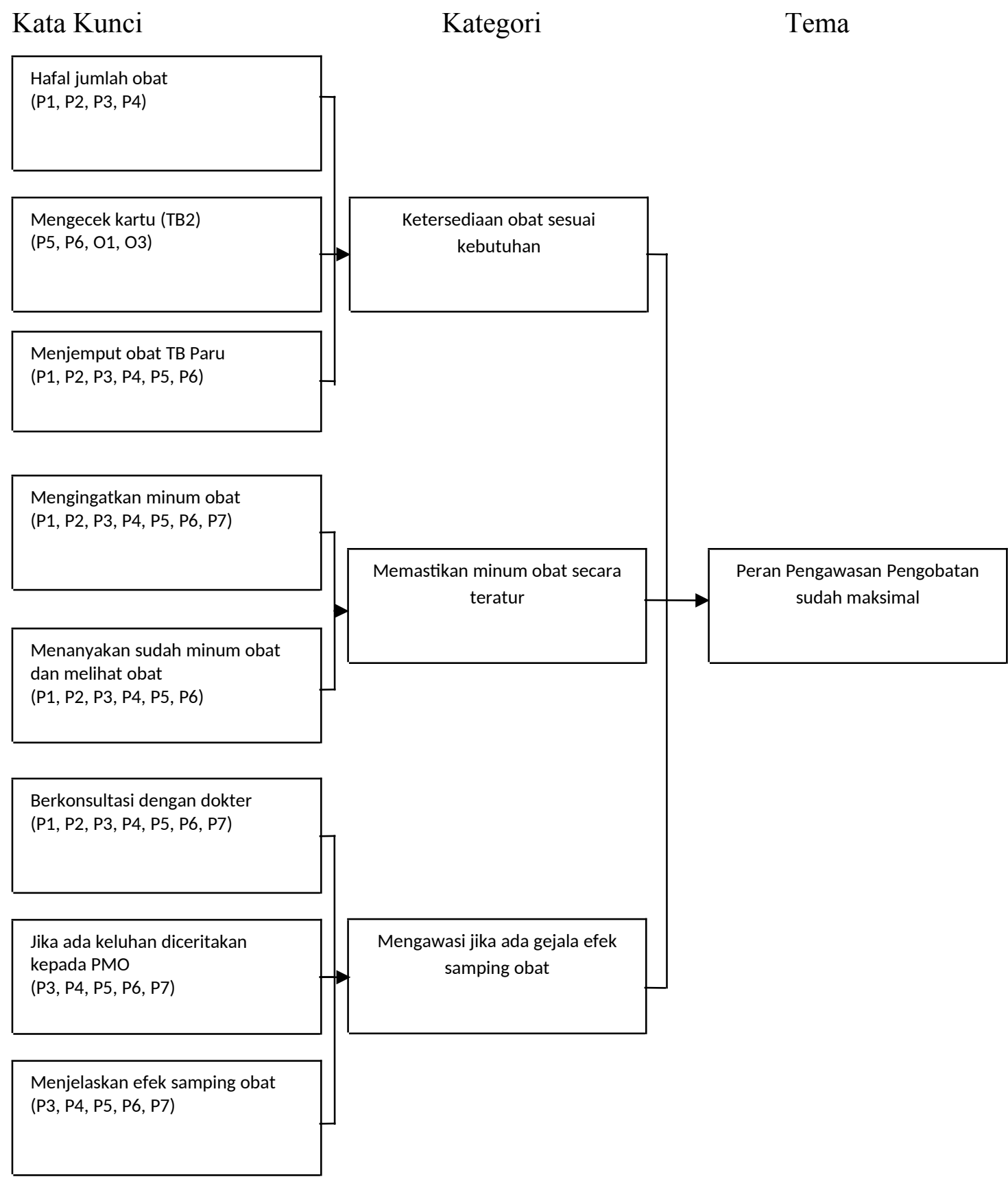

Skema 3

Analisa Tema Peran Pengawasan

\section{d. Peran Sebagai Edukator belum Maksimal}

Peran keluarga dalam memberi edukasi pasien TB Paru belum maksimal. Peneliti dapat 
mengidentifikasi tiga kegori yaitu Program TB Paru, Sosialisasi dari petugas kesehatan, dan pemahaman tentang aturan minum obat perlu dioptimalkan.

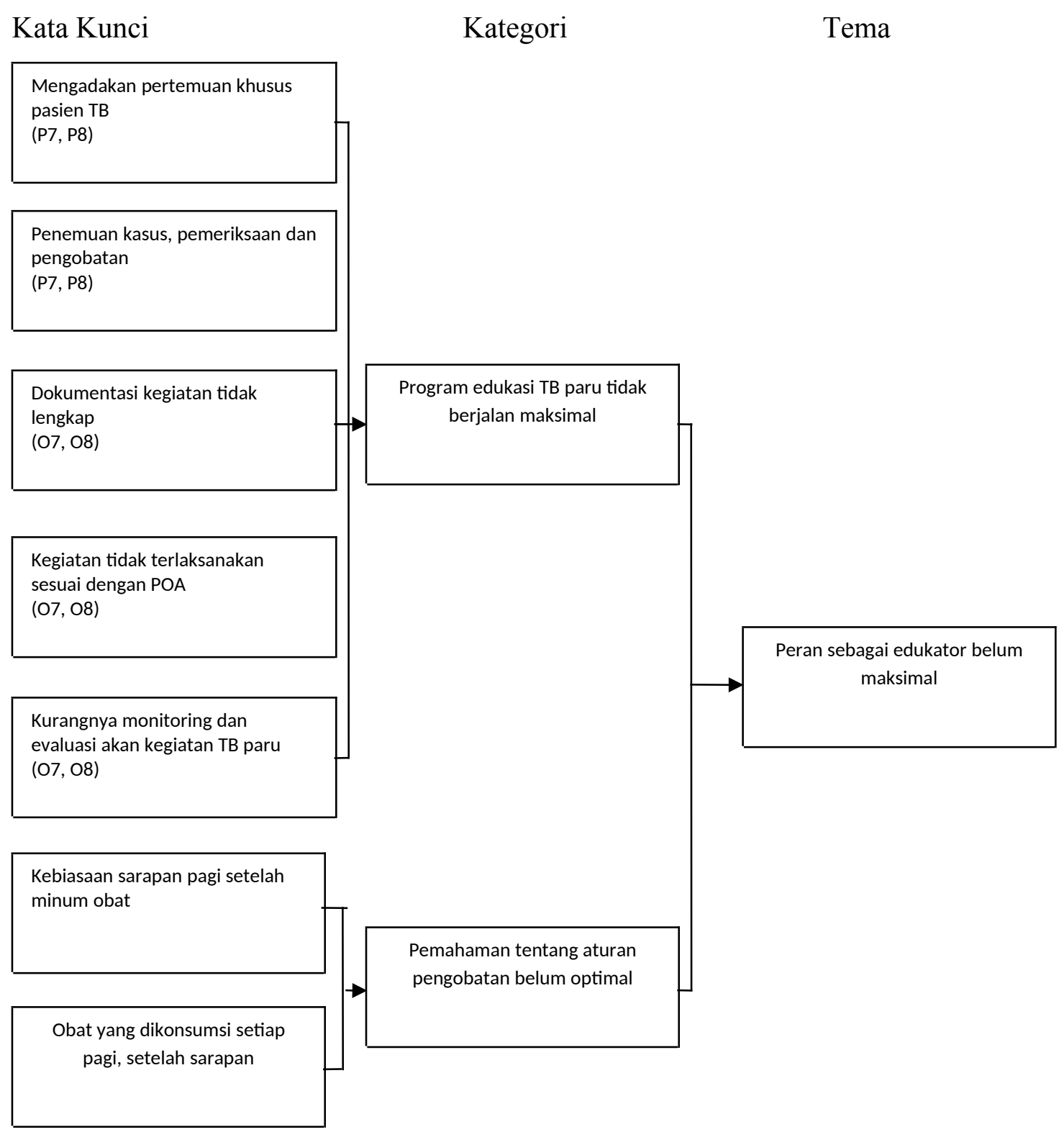

Skema 4

Analisa Tema Peran Keluarga sebagai Edukator Optimal 
Berdasarkan hasil penelitian teridentifikasi peran Keluarga sebagai PMO dalam memberikan motivasi atau dorongan agar pasien termotivasi untuk menjalani pengobatan sudah optimal. Pentingnya pengobatan sesuai aturan serta keinginan keluarga dan pasien yang sangat tinggi akan kesembuhan pasien menjadi motivasi bagi pasien TB paru untuk mencapai kesembuhan. Keluarga sebagai PMO dapat mendukung perilaku pasien dalam proses pengobatan, keteraturan berobat, dan kemauan untuk sembuh. Motivasi dilakukan agar pasien tidak putus asa dalam melakukan pengobatan, dan patuh dalam melaksanakan program pengobatan TB Paru. Motivasi yang diberikan kepada keluarga merupakan sesuatu hal yang menyebabkan dan yang mendukung tindakan atau perilaku seseorang (Stooner 1992 : Notoatmodjo 2014, p.119).

Berdasarkan hasil penelitian Menurut Hanan, $M$ \& Hidayat, $S$ (2013) Keluarga memotivasi pasien akan keteraturan minum obat, kontrol dan pengawasan minum obat.

Pemberian motivasi oleh keluarga kepada penderita dalam hal keteraturan obat sebagian besar memberikan motivasi akan pentingnya minum obat, mengingatkan penderita minum obat, obat harus diminum, dan supaya memudahkan penderita dalam minum obat. Berdasarkan hasil penelitian Nugroho, R.A (2011) sebagian besar partisipan mempunyai motivasi yang tinggi terhadap pengobatan TB. Sebagian besar partisipan mendapatkan dukungan keluarga. Dukungan keluarga tersebut terwujud melalui dukungan emosional, dukungan penghargaan, dukungan instrumental, dan dukungan informatif. Dukungan emosional meliputi empati, kepedulian, dan perhatian.
Menurut asumsi peneliti, peran keluarga dalam memotivasi pasien TB Paru sangat memberikan dampak positif terhadap pengobatan pasien. Secara psikologis, kedekatan batin antara anggota keluarga menjadikan dukungan berupa harapan kesembuhan dan keinginan keluarga untuk melihat pasien dapat beraktifitas kembali menjadikan motivasi kepada pasien. Keinginan kesembuhan bagi pasien terlihat dari kemauan PMO untuk memotivasi pasien agar tidak jenuh dan putus asa selama proses pengobatan. Lamanya proses pengobatan, dan pengobatan yang harus teratur, serta adanya efek samping obat dan keluhan kesehatan bagi pasien, mengharuskan adanya peran aktif dari keluarga, terutama dalam memotivasi pasien. Pasien akan termotivasi untuk berobat secara teratur disaat pasien dan PMO samasama mengharapkan kesembuhan pasien.

\section{Peran Mengingatkan Pemeriksaan Ulang Sputum sudah Optimal}

Berdasarkan hasil penelitian, peran keluarga sebagai PMO dalam mengingatkan pemeriksaan ulang sputum sesuai dengan jadwal pemeriksaan dilaksanakan sesuai anjuran Puskesmas sudah optimal. Keluarga mengingatkan pasien TB untuk pemeriksaan ulang sputum agar dapat menentukan keberhasilan pengobatan. Ketepatan jadwal pemeriksaa merupakan kunci kelanjutan pengobatan dan penentu keberhasilan dari suatu pengobatan. Keluarga sebagai PMO sangat berperan mengingatkan pasien terutama jika pasien tidak mampu atau berhalangan saat jadwal pemeriksaan sesuai yang telah ditetapkan oleh petugas kesehatan. Keluarga berpartisipasi dalam mengantar ke 
petugas kesehatan terdekat dan melakukan pemeriksaan laboratorium. Karena nantinya kesembuhan dinyatakan apabila pasien telah melakukan pemeriksaan ulang lengkap minimal dua kali selama pengobatan. Pemantauan kemajuan dan hasil pengobatan pada orang dewasa dilaksanakan denagn pemeriksaan ulang dahak secara mikroskopis (Kemenkes RI 2014, p.26 ) .

Berdasarkan dari penelitian yang dilakukan Erlinda, R. Dkk (2014) adanya hubungan antara peran Pengawas Minum Obat (PMO) dengan hasil apusan BTA pasien TB Paru. Hasil apusan BTA pada pemeriksaan ulang dahak di bulan kedua sangatlah penting karena hasil pemeriksaan sebagai penentu lanjutan pengobatan. Maka dari itulah peran keluarga sangatlah dibutuhkan dalam mengawasi pemeriksaan ulang dahak, agar tercapai kesembuhan dan mencegah terjadinya resistan obat. Keluarga sebagai PMO akan mengingatkan pasien untuk pemeriksaan ulang dahak sesuai dengan anjuran dari Fasilitas Kesehatan baik Puskesmas maupun Rumah Sakit. Kesibukan dan aktifitas pasien serta kondisi fisik dan kesehatan yang tidak dapat mengakibatkan atau berpotensi mengakibatkan terlupanya jadwal pemeriksaan. Oleh sebab itu, pemeriksaan ulang harus diingatkan oleh PMO agar proses pengobatan sesuai dengan aturan pengobatan pasien TB.

\section{Peran Pengawasan Pengobatan sudah Maksimal}

Berdasarkan hasil penelitian didapatkan bahwa peran pengawasan yang dilakukan keluarga sebagai PMO terhadap pengobatan sudah maksimal. Peran keluarga dalam mengawasi pengobatan pasien TB tidak hanya mengawasi keteraturan minum obat bagi pasien, tetapi juga mengawasi ketersediaan obat di rumah pasien. PMO dapat mengecek jumlah obat, melakukan pengecekan kartu TB 02, bahkan menjemput obat ke Puskesmas. Menurut Istiawan, dkk (2006) menyatakan bahwa langkah yang paling tepat agar berhasil dalam pengobatan diperlukan kepatuhan dalam minum obat anti tuberculosis secara teratur dan dibutuhkan Pengawas Minum Obat yang efektif. Dalam pengobatan, efek samping obat dapat mengganggu pasien untuk teratur menelan obat. Keluarga adalah yang pertama mengetahui efek samping obat. Efek samping obat yang mungkin timbul setelah minum obat anti tuberkulosis seperti pusing, mual, munntah-muntah, gatal-gatal, mata kabur dan nyeri otot/tulang biasanya disampaikan kepada PMO untuk dikonsultasikan ke petugas kesehatan. Keluarga sangat efektif mengawasi dalam kepatuhan dan keteraturan minum obat bagi pasien TB Paru. Berdasarkan hasil penelitian Debby, R, dkk (2014) mengenai peran PMO dalam meningkatkan kepatuhan minum obat pada pasie TB Paru, diperoleh yaitu pada umumnya partisipan mendampingi dan mengawasi pasien setiap harinya, hal ini dikarenakan partisipan adalah keluarga terdekat dari pasien, sehingga setiap hari dapat dipantau dengan mudah oleh partisipan yang merupakan PMO pasien TB paru. Partisipan pada umumnya juga mengingatkan pasien untuk minum obat. Biasanya partisipan mengingatkan pasien secara langsung agar lebih efektif dan pasien tidak lupa untuk meminum obat. Keteraturan pengobatan adalah kunci utama tercapainya kesembuhan. Peran Keluarga terhadap pengawasan sangatlah penting karena pengobatan 
TB Paru yang dilakukan minimal selama enam bulan, sangat membutuhkan peran keluarga dalam mengawasi ketersediaan obat dan keteraturan meminum obat dan jika ada gejala efek samping obat yang mengganggu kenyamanan pasien menkonsumsi obat.

\section{Peran sebagai Edukator belum Maksimal}

Berdasarkan hasil penelitian, peran keluarga sebagai edukator belum maksimal. Hal ini dikarenakan pelaksanaan program penanggulangan TB Paru di Puskesmas Ophir kurang dimonitor dan dievaluasi oleh pemegang program dan Kepala Puskesmas. Kegiatan program TB Paru yang dilaksanakan dengan pengadakan pertemuan khusus pasien $\mathrm{TB}$, penemuan kasus TB, pemeriksaan laboratorium, serta pengobatan TB Paru yang dilaksanakan oleh Puskesmas kurang di monitoring dan dievaluasi. Hasil dokumentasi dari seluruh kegiatan juga tidak lengkap. Program TB Paru dan Sosialisasi yang dilaksanakan bertujuan untuk terjaringnya pasien TB paru dan dilakukan edukasi kepada mereka agar pemahaman mengenai TB Paru di Puskesmas lebih maksimal. Berdasarkan hasil penelitian, kurangnya monitoring dan evaluasi serta ketidak pahaman pasien dan PMO mengidentifikasi peran sebagai edukator di Puskesmas Ophir belum maksimal. Menurut Depkes RI (2008) dalam program penanggulangan $\mathrm{TB}$ Paru, penyuluhan langsung perorangan sangatlah penting untuk menentukan keberhasilan pengobatan. Selain itu Efendi \& Makhfudli (2013) mengemukakan bahwa sebagai pendidik dan pelaksana konseling keperawatan perawat melaksanakan fungsi sebagai memberikan informasi kepada pasien. Melaksanakan penyuluhan atau pendidikan kesehatan untuk pemulihan kesehatan klien antara lain tentang pengobatan, hygiene, perawatan, serta gejala dan tanda-tanda bahaya. Berdasarkan hasil penelitian Debby, R, dkk (2014) mengenai peran PMO dalam meningkatkan kepatuhan minum obat pada pasien TB Paru, umumnya partisipan memberikan pengarahan kepada pasien setelah ikut mendampingi pasien ke Puskesmas. Pengarahan diberikan terlebih dahulu dari petugas kesehatan. Petugas kesehatan biasanya memberikan edukasi kepada PMO dan Pasien. Pada penelitian yang dilakukan Nugroho, R.A (2011) semua partisipan sudah mendapatkan pengarahan namun semua partisipan tidak mengetahui tahapan pengobatan TB Paru. Kejadian DO (Drop Out) pengobatan sebagai respon penderita terhadap rendahnya pengetahuan tentang TB Paru dan pengobatan TB Paru. Kebiasaan meminum obat setelah sarapan merupakan gambaran kekurang pahaman akan aturan pengobatan. Hal ini mengidentifikasi bahwa pemahaman keluarga belum optimal dan msih perlu pemberian informasi secara berkesinambungan serta adanya monitoring dan evaluasi dari Puskesmas. Kegiatan monitoring dilakukan dengan melihat hasil dokumentasi kegiatan, laporan kegiatan, serta feedback dari masyarakat terutama pasien dan PMO mengenai pemahaman akan TB Paru dan aturan minum Obat Anti Tuberkulosis (OAT). Peran sebagai edukator jika dilakukan keluarga secara maksimal akan memaksimalkan pemahaman pasien TB paru akan aturan minum obat.

\section{KESIMPULAN DAN SARAN}

\section{Kesimpulan}

Berdasarkan hasil penelitian tentang peran keluarga sebagai PMO 
di Puskesmas Ophir Kecamatan Luhak Nan Duo Kabupaten Pasaman Barat tahun 2016 didapatkan empat buah tema yaitu, peran sebagai motivator sudah optimal, peran mengingatkan pemeriksaan ulang sputum sudah optimal, peran pengawasan pengobatan sudah maksimal, peran sebagai edukator belum maksimal.

\section{Saran}

\section{Bagi Puskesmas}

Peran keluarga sebagai PMO sudah sangat efektif di Puskesmas, diharapkan Puskesmas dapat mengevaluasi pemahaman keluarga sebagai PMO terhadap proses pengobatan bagi pasien TB Paru, serta melakukan peningkatan penyuluhan dan sosialisasi kepada masyarakat tentang penyakit TB Paru dan TB MDR.

\section{DAFTAR PUSTAKA}

Afiyanti, Y \& Imami. N. R, 2014, Metodologi Penelitian Kualitatif Dalam Riset

Keperawatan. Jakarta : PT Raja Grafindo Persada.

Brink,P .J \& Wood, M. J, 2000. Langkah Dasar dalam Perencanaan Riset Keperawatan, Jakarta : Penerbit Buku Kedokteran EGC

Bustami, 2011, Penjaminan Mutu Pelayanan Kesehatan \& Askeptabilitasnya, Jakarta : Erlangga.

Depkes RI, 2008, Pedoman Pengobatan Dasar Di Puskesmas, Padang:Depkes Provinsi Sumbar. , 2007, Pedoman Nasional

Penanggulangan Tuberkulosis, Jakarta : Depkes RI. , 2002, Pedoman Nasional Penanggulangan Tuberkulosis. Jakarta : Depkes RI.

Debby, R. dkk, 2014. Peran Pengawas Menelan Obat (PMO) Tuberkulosis dalam meningkatkan Kepatuhan

\section{Bagi PMO}

Diharapkan PMO meningkatkan pengetahuan mengenai TB Baru. PMO juga diharapkan dapat meningkatkan pengawasan terhadap minum obat pasien yang merupakan anggota keluarga.

\section{Bagi Pasien}

Diharapkan pasien dapat meningkatkan kepatuhan akan minum obat, serta meningkatkan pengetahuan akan penyakit TB Paru, pencegahan penularan, serta pengobatan TB Paru sesuai aturan.

\section{Bagi Peneliti selanjutnya}

Karena keterbatasan peneliti, diharapkan peneliti selanjutnya dapat meneliti secara mendalam mengenai peran keluarga terhadap pasien TB Paru dengan HIV positif dan pasien TB MDR.

Minum Obat pada Pasien

Tuberkulosis Paru di kelurahan

Sidomulyo Barat Pekanbaru. Dari

:http://download.portalgar uda.org/ article

Erlinda, R, dkk. 2013. Hubungan Peran Pengawas Minum Obat (PMO) dalam Program DOTS dengan Hasil Apusan BTA Pasien Tuberkulosis Paru di Puskesmas Tanggul Kabupaten Jember. $\quad$ Dari: http//download.portalgaru da.org/article.

Hannan, M \& Hidayat, S, 2013, Peran Keluarga Dalam Perawatan Penderita Tuberculosis Paru Di Kecamatan Gapura Kabupaten Sumenep. MKM Vol.02 No. 01 Juni 2007. Sumenep : Unija, dari : http//download.portalgaru da.org/article

Irma, 2014, Studi Kualitatif Tentang Pengalaman Anggota Keluarga Merawat Pasien TB Paru di Wilayah Kerja Puskesmas Moncobalang Kecamatan 
Borombongan Kabupaten Gowa, Makasar : FK Unhas dari : https://repository.unhas. ac.id / 2014

Istiawan, R. dkk, 2005, Hubungan Peran PMO Oleh Keluarga Dan Petugas Kesehatan

Terhadap Pengetahuan, Perilaku Pencegahan dan Kepatuhan Klien TBC Dalam Konteks

Keperawatan Komunitas Di Kabupaten Wonosobo, Journal Keperawatan

Soedirman Volume 1, No 2, November 2006, Jawa Tengah : UI, dari :http://download.portalgar uda.org

Kemenkes RI, 2004 Pedoman Nasional Pengendalian Tuberkulosis, Jakarta: Direktorat Jenderal P2PL. , 2011, Strategi Nasional Pengendalian TB, Jakarta : Direktorat Jenderal P2PL 2014, Pedoman

Nasional Pengendalian

Tuberkulosis, Jakarta : Direktorat Jenderal P2PL , 2014 Pedoman Nasional Pengendalian Tuberkulosis, Jakarta: Direktorat Jenderal P2PL. 2015, Tuberkulosis

Temukan Obati Sampai Sembuh, Jakarta : Pusat Data Dan Informasi Kementrian Kesehatan RI.

Temukan Obati Sampai Sembuh,Jakarta : Pusat Data Dan Informasi Kementrian Kesehatan RI.

Limbu, R \& Marni, 2007, Peran Keluarga Sebagai Pengawas Minum Obat (PMO) Dalam Mendukung Proses Pengobatan Penderita TB Paru di Wilayah Kerja Puskesmas Baumata Kecamatan Taebenu Kabupaten Kupang. MKM Vol.02 No. 01 Juni 2007, dari

https://mediakesehatanma

syarakat.files.wordpress.com/201 2

Notoatmojo, S, 2010, Metodologi Penelitian Kesehatan, Jakarta :
Rineka Cipta. Nugroho, A.R, 2011, Studi Kualitatif Faktor yang Melatarbelakangi Drop Out Pengobatan

Tuberkulosis Paru. Kemas 7 (1) (2011) 83-89. dari

http://journal.unnes.ac.id/i ndex.phi/kemas

Pare, A, L.dkk, 2012, Hubungan Antara Pekerjaan, PMO, Pelayanan Kesehatan, Dukungan Keluarga, dan Diskriminasi Dengan Perilaku Berobat Pasien TB Paru, Makasar : Unhas, dari https://repository.unhas.ac.id/2012

PPTI, 2010, Buku Saku PPTI (Perkumpulan Pemberantasan Tuberkulosis Indonesia), Jakarta : PPTI PPTI, 2010, Jurnal Tuberkulosis Indonesia, Jakarta : PPTI, dari

https://agus34drajat.files.wordpres s.com/.../jurnaltuberkulosisindonesia

Puskesmas Ophir, 2015, Profil UPT Puskesmas Ophir, Pasaman Barat : Puskesmas Ophir

Rachmawati,T \& L, 2006, Turniati, Pengaruh Dukungan Sosial dan Pengetahuan tentang Penyakit TB terhadap Motivasi Untuk Sembuh Penderita TB yang Berobat di Puskesmas, Surabaya : Puslitbang, dari : http://ejournal.litbang.dep kes.go.id/index.php/hsr/article

Rahmawati, dkk, 2012, Peran PMO dalam Mencegah Penularan TB Paru di Wilayah Kerja Puskesmas Remaja Samarinda, Makasar : FKM Unhas, dari http://pasca.unhas.ac.id/jurnal/file

Risnanto, dkk, 2006, Perbandingan Persepsi Penderita Tuberkulosis Paru Terhadap Bahaya Penyakit, Manfaat Pengobatan dan Peran Pengawas Menelan Obat di Puskesmas Kabupaten Tegal, dari : www.stikesbhamada.ac.id/ ojs/index.php/jitk/article/view/2006 
Suryana, A, 2007 Tahapan-Tahapan Penelitian Kualitatif, Jakarta : Fakultas Ilmu Pendidikan UPI Sahid, R, 2011, Analisa Data Penelitian Kualitatif Model Miles dan Huberman, dari: http://sangit26.blogspot.co.id/2011 107

Sidy, N. Y. 2012. Analisis Pengaruh Peran Pengawas Menelan Obat dari Keluarga dengan Kepatuhan Pengobatan

Penderita Tuberkulosis di
Yohanes, D \& Yasinta, 2013, Asuhan Keperawatan Keluarga Konsep dan Praktik. Yogyakarta : Nuha Medika

Yoisangadji, S. A, dkk, 2016, Hubungan Pengawas Menelan Obat (PMO) dan Peran Keluarga dengan Kepatuhan Minum Obat pada Pasien di Wilayah Kerja Puskesmas Sario Kota Manado. UNSRAT Vol. 5 No. 2 Mei 2016 ISSN 2302-2493, Manado : Universitas Samratulanngi, dari : http://e.journal.unsrat.ac.id/index.p hp/pharmacon

Kota Pariaman Tahun 2010- 2011. Jakarta : FKM UI, dari : http://lib.ui.ac.id/file?file=digital/20 313573-T3131 Analisis pengaruh.pdf 